Revista Brasileira de Agricultura Irrigada v.14, nº.3, p. 4036 - 4046, 2020

ISSN 1982-7679 (On-line)

Fortaleza, CE, INOVAGRI - http://www.inovagri.org.br

DOI: $10.7127 /$ rbai.v14n101139

Protocolo 1139.20 - 11/04/2020 Aprovado em 29/10/2020

\title{
CRESCIMENTO INICIAL DA CULTURA DA FAVA IRRIGADA SOB ESTRESSE SALINO E HÍDRICO
}

João Valdenor Pereira Filho ${ }^{1}$, Andreza de Melo Mendonça ${ }^{2}$, Geocleber Gomes de Sousa ${ }^{3}$, Thales Vinícius de Araújo Viana ${ }^{4}$, Rute Maria Rocha Ribeiro ${ }^{5}$, Juvenaldo Florentino Canjá6.

\section{RESUMO}

O estresse salino associado ao hídrico afetam o crescimento e a produtividade das culturas agrícolas. O trabalho teve por objetivo avaliar a resposta da cultura da fava (Phaseolus lunatus L.), cultivar Espírito Santo, quanto ao estresse salino e hídrico no crescimento, acúmulo de biomassa fresca, $\mathrm{pH}$ e condutividade elétrica do solo. O experimento foi conduzido na área experimental no município de Fortaleza, Ceará, no período de setembro a novembro de 2017, sendo realizado em vasos a pleno sol, sob um delineamento estatístico inteiramente casualizado em parcelas subdivididas. Os dois regimes hídricos (parcelas) foram baseados pela evapotranspiração potencial da cultura (100 e 50\% da ETc). Já os níveis de salinidade da água de irrigação $\left(1,1 ; 2,1,3,1,4,1\right.$ e 5,1 dS m$\left.{ }^{-1}\right)$ foram distribuídos nas subparcelas. Aos 45 dias após a semeadura (DAS) foram analisadas as seguintes variáveis: altura das plantas, diâmetro do caule, número de folhas, área foliar, massa seca da parte aérea, $\mathrm{pH} \mathrm{e}$ condutividade elétrica do solo. O crescimento inicial da cultura foi prejudicado pelo aumento da concentração de sais na água de irrigação, quando cultivada sob regime hídrico de $50 \%$ da ETc. A condutividade elétrica do solo é elevada pela redução no manejo da irrigação com águas salinas no regime hídrico de 100 para 50\% da ETc.

Palavras-chave: Phaseolus lunatus L., salinidade da água, déficit hídrico.

\footnotetext{
${ }^{1}$ Prof. Doutor em Engenharia Agrícola, Universidade Federal do Piauí, CEP: 64049-550, Campus Universitário Ministro Petrônio Portella, Teresina - PI, Brasil. E-mail: joao_valdenor@ hotmail.com

${ }^{2}$ Mestranda em Ciências do Solo, Universidade Federal do Ceará, CEP: 60020-181, Av. da Universidade, 2853 Benfica, Fortaleza - CE, Brasil. E-mail: andreza.melo2911@gmail.com

${ }^{3}$ Prof. Doutor em Engenharia Agrícola, Universidade da Integração Internacional da Lusofonia Afro-Brasileira, CEP: 62790-000, Av. Abolição, Redenção, CE, Brasil. E-mail: sousagg@unilab.edu.br

${ }^{4}$ Prof. Doutor em Engenharia Agrícola, Universidade Federal do Ceará, CEP: 60020-181, Av. da Universidade, 2853 Benfica, Fortaleza - CE, Brasil. E-mail: thales@ufc.br

${ }^{5}$ Graduanda em Agronomia, Universidade da Integração Internacional da Lusofonia Afro-Brasileira, CEP: 62790-000, Av. Abolição, Redenção, CE, Brasil. E-mail: rutemaryrocha@gmail.com

${ }^{6}$ Mestrando em Engenharia Agrícola, Universidade Federal do Ceará, CEP: 60020-181, Av. da Universidade, 2853 -

Benfica, Fortaleza - CE, Brasil. E-mail: batchijuve@gmail.com
} 


\title{
INITIAL GROWTH OF FAVA CULTURE IRRIGATED UNDER SALINE AND WATER STRESS
}

\begin{abstract}
The salt stress associated with water affects the growth and productivity of agricultural crops. The objective of this work was to evaluate the response of fava (Phaseolus lunatus L.) cultivar, Espírito Santo, in relation to saline and water stress on growth, biomass accumulation, $\mathrm{pH}$ and soil electrical conductivity. The experiment was carried out in the experimental area of the Agrometeorological Station of the Department of Agricultural Engineering, belonging to the Federal University of Ceará (UFC) in the city of Fortaleza, Ceará, Brazil, from September to November 2017, a completely randomized design in subdivided plots, where the salinity levels $\left(1.1,2.1,3.1,4.1\right.$ and $\left.5.1 \mathrm{dS} \mathrm{m}^{-1}\right)$ were considered as plots, as well as water treatments were: 100 and $50 \%$ of the evaporation of water from the Class A tank (ECA) in the subplots. At 45 days after sowing (DAS), the following variables were analyzed: plant height, stem diameter, leaf number, leaf area, shoot dry mass, $\mathrm{pH}$ and soil electrical conductivity. The initial growth of the crop was further impaired by the increase in the concentration of salts in irrigation water when cultivated under a 50\% ETc water regime. The electrical conductivity of the soil is increased by the reduction in the irrigation management with saline waters in the water regime from 100 to $50 \%$ of the ETc.
\end{abstract}

Key words: Phaseolus lunatus L., water salinity, water deficit.

\section{INTRODUÇÃO}

A fava (Phaseolus lunatus L.) é uma leguminosa cultivada em quase todas as regiões do mundo, sendo muito consumida na América Latina, nos Estados Unidos, na Europa e Ásia. No Brasil possui ampla distribuição no território nacional, estando presente em todos os biomas brasileiros. Entretanto, é cultivada principalmente no Nordeste, possuindo boa adaptação à região semiárida (OLIVEIRA et al., 2011).

De acordo com dados IBGE, no ano de 2016 foram produzidas, no Brasil, $3.637 \mathrm{t}$ de fava, sendo a região Nordeste responsável por 99,23\% da produção, destacando-se como principais produtores os Estados da Paraíba, Ceará e Pernambuco, respectivamente. Nestas regiões, muitos autores têm discutido o efeito da salinidade do solo e da água sobre o desenvolvimento das plantas tendo em vista que é considerado como um dos principais problemas, bem como o manejo correto da água, levando em consideração o déficit e escassez de recursos hídricos (COSTA; MEDEIROS, 2017).

A sensibilidade do feijão-fava ao déficit hídrico no solo e as incertezas climáticas, principalmente as relacionadas às variações pluviométricas estimulam cada vez mais a realização de pesquisas na área, uma vez que, durante os períodos de alta demanda hídrica, a extração de água pelas plantas pode ser insuficiente devido ao esgotamento da água no solo, onde esta localizada a zona radicular e à acumulação de sais refletindo na salinidade limiar que na fava é $1,5 \mathrm{dS} \mathrm{m}{ }^{-1}$ tendo também em vista a importância da cultura em algumas comunidades (OLIVEIRA, et al., 2014).

Pereira Filho et al. (2017) avaliando o crescimento vegetativo de duas cultivares de feijão-caupi cultivadas sob níveis de salinidade da água de irrigação associados a dois regimes hídricos, constataram que o aumento da concentração de sais da água de irrigação promoveu reduções lineares nas variáveis altura das plantas, diâmetro do caule, número de folhas, área foliar e produção de matéria seca da parte aérea.

Objetivou-se com este trabalho avaliar as características de crescimento vegetativo inicial e parâmetros do solo na cultura da fava cultivada em vasos sob níveis de salinidade da água de irrigação associados a dois regimes hídricos. 


\section{MATERIAL E MÉTODOS}

O experimento foi conduzido na área experimental da Estação Agrometeorológica do Departamento de Engenharia Agrícola, pertencente a Universidade Federal do Ceará (UFC), no município de Fortaleza, estado do Ceará, com coordenadas geográficas $03^{\circ} 45^{\prime} \mathrm{S}$, $38^{\circ} 33^{\prime} \mathrm{W}$, altitude média $19 \mathrm{~m}$, no período de setembro a novembro de 2017. O clima da região, segundo a classificação de Köppen, é do tipo Aw', tropical chuvoso, com temperaturas elevadas e com estação chuvosa predominante no outono.

Como substrato para o cultivo das plantas, foi utilizado uma amostra de Solo Argiloso Vermelho-Amarelo, textura franco arenoso (FERNANDES, 1993), com densidade de $1,49 \mathrm{~g} \mathrm{~cm}^{-3}$ oriunda de uma área com vegetação nativa, localizada próximo a área experimental da Estação Agrometeorológica, cuja as características químicas encontram-se na Tabela

Tabela 1. Resultado da análise química do solo utilizado como substrato na realização do experimento.

\begin{tabular}{|c|c|c|c|c|c|c|c|}
\hline \multicolumn{8}{|c|}{ Complexo Sortivo $\left(\mathrm{cmol}_{\mathrm{c}} \mathrm{kg}^{-1}\right)$} \\
\hline $\mathrm{Ca}^{2+}$ & $\mathrm{Mg}^{2+}$ & $\mathrm{Na}^{+}$ & $\mathrm{K}^{+}$ & $\mathrm{H}^{+}+\mathrm{Al}^{3+}$ & $\mathrm{Al}^{3+}$ & $\mathrm{S}$ & $\mathrm{T}$ \\
\hline 1,20 & 0,60 & 0,23 & 0,36 & 1,98 & 0,15 & 2,6 & 4,6 \\
\hline pH em água & & $\mathrm{CE}\left(\mathrm{dS} \mathrm{m} \mathrm{m}^{-1}\right)$ & & & & & \\
\hline 6,0 & & 0,35 & & & & & \\
\hline $\mathrm{C}\left(\mathrm{g} \mathrm{kg}^{-1}\right)$ & $\mathrm{N}\left(\mathrm{g} \mathrm{kg}^{-1}\right)$ & $\mathrm{C} \mathrm{N}^{-1}$ & & $\left.\mathrm{~kg}^{-1}\right)$ & $\mathrm{Pa}$ & $\operatorname{vel}(\mathrm{n}$ & \\
\hline 6,48 & 0,61 & 11 & & & & 32 & \\
\hline
\end{tabular}

A aplicação dos fertilizantes químicos da fundação foi realizada, baseada na análise de solo e exigências nutricionais da cultura, obedecendo às prescrições de Aquino et al. (1993). As quantidades necessárias de macronutrientes foram às seguintes: $20,0 \mathrm{~kg}$ $\mathrm{ha}^{-1}$ de nitrogênio $(\mathrm{N}), 80,0 \mathrm{~kg} \mathrm{ha}^{-1}$ de fósforo (P) e $30,0 \mathrm{~kg} \mathrm{ha}^{-1}$ de potássio $(\mathrm{K})$, sendo utilizados como fontes a ureia, $\mathrm{O}$ fosfato monoamônio (MAP) e o cloreto de potássio, respectivamente.

A área útil total ocupada com a cultura da fava foi de $80 \mathrm{~m}^{2}$, onde foram instalados os 80 vasos plásticos, que possuíam volume de 14 litros cada. As parcelas ocupavam uma área útil de $20,0 \mathrm{~m}^{2}$, sendo composta por 20 vasos, distribuídos em cinco linhas de plantio. Já as subparcelas ocuparam, individualmente, uma área útil de 10,0 $\mathrm{m}^{2}$, sendo composta de dois vasos distribuídos por linha de plantio em cada tratamento de regime hídrico.

No plantio foram utilizadas sementes de fava, cultivar Espírito Santo realizado em vasos plásticos com capacidade de 14 litros. Após o estabelecimento das plantas aos oito dias após a semeadura (DAS), realizou-se o desbaste, deixando-se uma planta por vaso. $\mathrm{O}$ plantio foi feito semeando-se em média cinco sementes por vaso. Aos 7 dias após a semeadura (DAS), observou-se uma germinação de aproximadamente $90 \%$. No desbaste, realizado manualmente aos 10 DAS, às plantas foram arrancadas rente ao solo deixando-se duas plantas por vaso, de forma a se obter o estande de plantas almejado pelo experimento.

O delineamento estatístico foi o inteiramente casualizado em parcelas subdivididas, onde os tratamentos com os níveis de salinidade da água (CEa) $(1,1 ; 2,1$; 3,1; 4,1 e $5,1 \mathrm{dS} \mathrm{m}^{-1}$ ) foram considerados as parcelas, já os tratamentos de regime hídrico com 100 e $50 \%$ da evapotranspiração potencial da cultura - ETc ficaram distribuídos nas subparcelas.

A água utilizada para abastecimento do sistema de irrigação era proveniente de um poço cujo resultado da análise da qualidade da água para fins de irrigação foram: $1,3 \mathrm{mmol}_{\mathrm{c}}$ $\mathrm{L}^{-1} \mathrm{Ca}^{2+} ; 3,1$ mmol $_{\mathrm{c}} \mathrm{L}^{-1} \mathrm{Mg}^{2+} ; 4,5$ mmol $_{\mathrm{c}} \mathrm{L}^{-1}$ $\mathrm{Na}^{+} ; 0,4 \mathrm{mmol}_{\mathrm{c}} \mathrm{L}^{-1} \mathrm{~K}^{+} ; 5,2 \mathrm{mmol}_{\mathrm{c}} \mathrm{L}^{-1} \mathrm{Cl}^{-}$ referente aos cátions; 4,3 $\mathrm{mmol}_{\mathrm{c}} \mathrm{L}^{-1} \mathrm{HCO}^{3-}$ referente aos ânions; $\mathrm{CE}=0,95 \mathrm{dS} \mathrm{m}^{-1} ; \mathrm{RAS}=$ 3,$05 ; \mathrm{pH}=8,0 ;$ sólidos dissolvidos $=950 \mathrm{mg}$ $\mathrm{L}^{-1}$; classificação C3 S1. Pelo resultado, constatou-se que a água em questão apresenta 
alta salinidade (C3) e baixo conteúdo de sódio (S1).

O método de manejo de irrigação adotado foi via clima. Para a determinação da evapotranspiração de referência - ETo, adotouse a metodologia contida em Bernardo et al. (2008).

$\mathrm{ETo}=\mathrm{ECA} \times \mathrm{Kt}$

em que: ETo - Evapotranspiração de referência (mm); ECA - Evaporação do tanque classe " $A$ " (mm) e Kt - Coeficiente de ajuste do tanque (adimensional).

Para a obtenção do (Kt), foi utilizada a equação proposta por Snyder (1992), apresentada abaixo:

$\mathrm{Kt}=0,482+0,024 \ln (\mathrm{F})-0,000376 \mathrm{U}+0,0045 \mathrm{UR}$ (2)

em que: F - Distância do centro do tanque ao limite da bordadura (tanque circundado por grama a $10 \mathrm{~m}$ ); U - Velocidade média do vento a $2 \mathrm{~m}$ de altura $\left(\mathrm{km} \mathrm{dia}{ }^{-1}\right)$; UR Umidade relativa média do ar (\%).

Os dados climáticos necessários para o cálculo do $(\mathrm{Kt})$ foram obtidos mediante a média aritmética dos últimos cinco anos, para os meses nos quais o experimento foi conduzido, sendo coletados em uma estação meteorológica automatizada, localizada nas imediações da área experimental.

A evapotranspiração da cultura foi estimada (ETc), através da equação 3, mediante a multiplicação da evapotranspiração de referência e o coeficiente da cultura $(\mathrm{Kc})$, segundo Bernardo et al. (2008).

$\mathrm{ETc}=\mathrm{ETo} \mathrm{x} \mathrm{Kc}$

em que: $\mathrm{ETc}=$ evapotranspiração da cultura $(\mathrm{mm}) ;$ ETo = evapotranspiração de referência através do Tanque Classe $\mathrm{A}$, em $\mathrm{mm} ; \mathrm{Kc}=$ Coeficientes de cultivo

Após o plantio das sementes de feijãofava, o experimento foi irrigado diariamente com uma lâmina equivalente a $100 \%$ da evapotranspiração da referência - ETc, a fim de garantir o estabelecimento inicial da cultura, até o início da diferenciação dos tratamentos, que se deu aos 10 dias após o plantio - DAP, mediante a variação dos níveis de salinidade da água de irrigação, com uma frequência equivalente há dois dias consecutivos.

Em reservatórios com capacidade de $310 \mathrm{~L}$, a quantidade dos sais $\mathrm{NaCl}$, $\mathrm{CaCl}_{2} \cdot 2 \mathrm{H}_{2} \mathrm{O}, \quad \mathrm{MgCl}_{2} \cdot 6 \mathrm{H}_{2} \mathrm{O}$, utilizadas no preparo das águas de irrigação foi determinada de forma a se obter a CEa desejada na proporção 7:2:1 obedecendo a relação entre CEa e sua concentração $\left(\right.$ mmol $_{\mathrm{c}} \mathrm{L}^{-1}=\mathrm{CE}$ x 10$)$, conforme Rhoades et al., (2000).

Aos 45 dias após o plantio - DAP, a fim de mensurar os efeitos dos diferentes tratamentos sobre as características morfológicas das cultivares foram determinadas as seguintes variáveis: altura das plantas, considerada a distância entre o colo da planta e a emissão da folha mais nova, aferida por meio de trena graduada, expressa em $\mathrm{cm}$; diâmetro do caule, obtido pela medição a uma distância de aproximadamente 3 centímetros do colo da planta, sendo aferido por meio de paquímetro digital, expresso em $\mathrm{mm}$; número de folhas, obtido pela contagem manual a partir da folha $\mathrm{n}^{\mathrm{o}} 1$ a partir do ápice, expresso em unidades; área foliar, obtido através da utilização de um integrador de área (LI-3100, Li-Cor, Inc. Lincoln, NE, USA), expresso em $\mathrm{cm}^{2}$ planta $^{-1}$. Para a coleta dos dados de $\mathrm{pH}$ e condutividade elétrica, o solo de cada vaso foi homogeneizado e amostras foram utilizadas na determinação do $\mathrm{pH}$ e da condutividade elétrica do extrato de saturação (CEes), adotando-se a metodologia contida em Richards (1954).

Os resultados referentes aos níveis de condutividade elétrica e os regimes hídricos foram submetidos à análise variância (ANOVA), e quando se demostraram significativos pelo teste $\mathrm{F}$, foram submetidos ao teste de médias pelo teste de Tukey, por meio do programa estatístico ASSISTAT 7.7 Beta. 


\section{RESULTADOS E DISCUSSÃO}

Verifica-se a partir da análise de variância (Tabela 2) que todas as características vegetativas foram influenciadas significativamente pela interação entre os fatores salinidade e regimes hídricos a 1 e $5 \%$ de probabilidade pelo teste F; já para as variáveis do solo, apenas a CEes apresentou significância, isoladamente, para $o$ fator salinidade e regimes hídricos a 5 e $1 \%$ pelo teste $\mathrm{F}$, respectivamente.

Tabela 2. Resumo da análise de variância para os dados de altura das plantas (AP), diâmetro do caule (DC), número de folhas (NF), área foliar (AF) e massa seca da parte aérea (MSPA) da fava e dos parâmetros do solo, $\mathrm{pH}$ e condutividade elétrica, cultivado sob diferentes níveis de salinidade da água de irrigação e regimes hídricos.

\begin{tabular}{|c|c|c|c|c|c|c|c|c|}
\hline \multirow{2}{*}{$\mathrm{FV}$} & \multirow{2}{*}{ GL } & \multicolumn{7}{|c|}{ Quadrados médios } \\
\hline & & AP & $\mathrm{DC}$ & NF & $\mathrm{AF}$ & MSPA & $\mathrm{pH}$ & CEes \\
\hline Salinidade & 4 & $5730,71^{* *}$ & $2,40^{* *}$ & $138,02^{* *}$ & $466500,55^{* *}$ & $647,89^{* * *}$ & $0,63^{\mathrm{ns}}$ & $67,21^{*}$ \\
\hline Resíduo & 15 & 21,04 & 0,06 & 1,49 & 4391,09 & 3,72 & 0,29 & 16,52 \\
\hline Parcelas & 19 & & & & & & & \\
\hline Regime Hídrico (RI) & 1 & $6225,02^{* *}$ & $3,31^{* *}$ & $145,35^{* *}$ & $590395,96^{* *}$ & $687,13^{* *}$ & $0,01^{\mathrm{ns}}$ & $31,86^{* *}$ \\
\hline Int. S x RI & 4 & $80,46^{* *}$ & $0,10^{*}$ & $12,71^{* *}$ & $33319,71^{* *}$ & $47,05^{\text {** }}$ & $0,07^{\mathrm{ns}}$ & $6,15^{\mathrm{ns}}$ \\
\hline Resíduo & 15 & 6,97 & 0,02 & 0,85 & 1823,94 & 2,05 & 0,04 & 2,45 \\
\hline Total & 39 & & & & & & & \\
\hline $\mathrm{CV}-\mathrm{S}(\%)$ & & 7,14 & 5,52 & 12,61 & 13,02 & 9,54 & 8,37 & 64,61 \\
\hline $\mathrm{CV}-\mathrm{I}(\%)$ & & 4,11 & 3,45 & 9,53 & 8,39 & 7,08 & 3,14 & 24,9 \\
\hline
\end{tabular}

FV: Fontes de variação; GL: Graus liberdade; (*) Significativo pelo teste F a 5\%; (**) Significativo pelo teste F a 1\%; ns: não significativo; C.V.: Coeficiente de variação.

$\mathrm{Na}$ Figura 1A verifica-se um decréscimo na altura das plantas, representado por um modelo matemático linear, mediante $o$ aumento nos níveis de salinidade da água de irrigação, para os regimes hídricos de $50 \%$ e $100 \%$ da ETc. Resultados semelhantes foram apresentados por Pereira Filho et al. (2017) que também constataram uma redução na altura das plantas de feijão-caupi na interação entre os mesmos fatores (salinidade $\mathrm{x}$ regime hídrico) adotados nesta pesquisa.

Pereira et al., (2012) afirmam que o aumento da concentração de sais no substrato determina redução no potencial hídrico, resultando em menor capacidade de absorção de água pelas plantas, o que geralmente influência no desenvolvimento das culturas. Nessa condição, observa-se que no tratamento de regime hídrico de $50 \%$ da ETc, a altura das plantas é mais acentuadamente reduzida, devido aos efeitos conjuntos do estresse hídrico e salino.

Analisando-se o efeito das diferentes concentrações de sais na água de irrigação para os regimes hídricos de 100 e $50 \%$ da ETc (Figura 1B), constatou-se uma redução no número de folhas para ambos os regimes hídricos, com decréscimos de 18,9 e $15,2 \mathrm{~cm}$ para 100 e $50 \%$ da ETc, sendo que a equação que melhor representou a resposta das plantas foi do tipo linear. Resultados semelhantes aos de Oliveira et al. (2015) que avaliando o crescimento inicial do pinhão manso, verificaram que o número de folhas foi reduzido em resposta ao aumento da condutividade elétrica da água de irrigação (CEa).

A diminuição no número de folhas pode estar relacionada ao menor crescimento devido à restrição no processo de absorção; como consequência, ocorre redução do fluxo de água no sentido solo-planta-atmosfera ocasionando alterações morfológicas e anatômicas na planta (COELHO et al., 2013).

Tester e Davenport (2003) relatam que este decréscimo, possivelmente, está relacionado com um dos mecanismos de adaptação da planta ao estresse salino. A diminuição do número de folhas do feijão fava sob condições de estresse salino é um mecanismo de extrema importância, para manutenção de elevado potencial hídrico na planta, obtido através da diminuição na superfície transpirante. 


\section{Pereira Filho et al.}
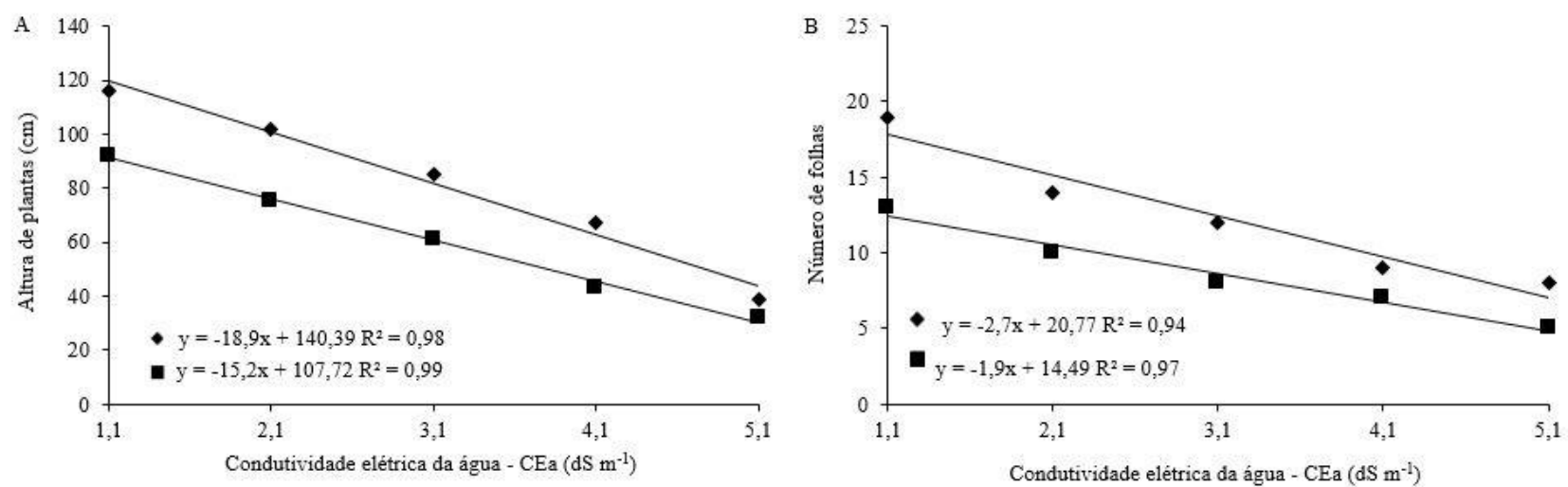

Figura 1. Área foliar de plantas(1A) e número de folhas (1B) de fava irrigada com água salina sob diferentes regimes hídricos $-100 \%$ ( ) e 50\% ETc (ロ) aos 45 dias após o plantio.

$\mathrm{Na}$ Figura 2A observa-se um decréscimo no diâmetro do caule em função das diferentes concentrações de sais na água de irrigação, para os regimes hídricos de $100 \%$ e $50 \%$ da ETc, sendo a equação que melhor representou a resposta das plantas do tipo linear. Similarmente, Sousa et al. (2015) estudando a cultura do feijão caupi, também constataram uma redução no diâmetro do caule nos mesmos regimes hídricos adotados nesta pesquisa.

A redução do diâmetro do caule das plantas nos dois regimes hídricos $(100 \%$ e $50 \%$ da ETc), evidencia uma resposta da cultura da fava ao estresse hídrico e salino, como forma de garantir a absorção de água do solo para manter, parcialmente, a atividade fisiológica das plantas (GARCIA et al., 2009).

A resposta da área foliar do feijão fava

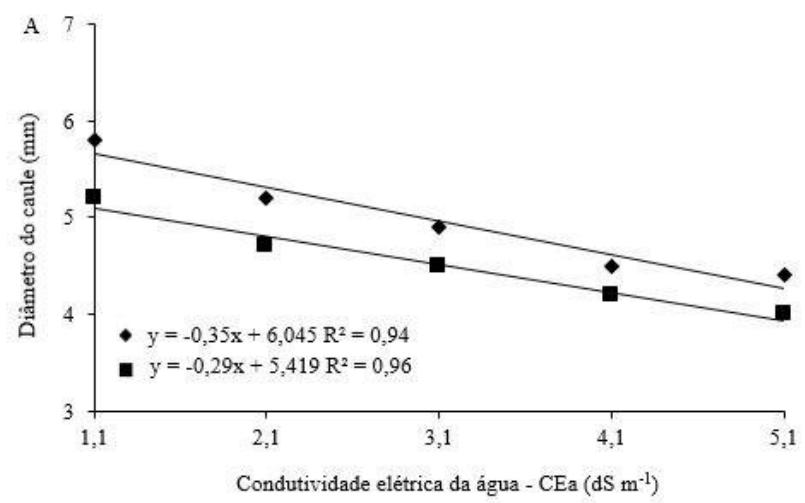

na interação entre os regimes hídricos e concentrações de sais da água de irrigação pode ser observada na Figura 2B. O modelo matemático que expressou os dados desta variável foi o linear decrescente, independente do regime hídrico empregado, sendo percebido uma redução mais acentuada no regime hídrico de 50\% da ETc. Silva et al. (2017) avaliando o efeito de concentrações de sais da água de irrigação $\left(0,2,4,8\right.$ e $\left.16 \mathrm{dS} \mathrm{m}^{-1}\right)$ também constataram reduções na área foliar na cultura da alface crespa.

Conforme Taiz et al. (2017), com o número de folhas reduzidas, a planta transpira menos, conservando um suprimento de água limitado no solo por um período mais longo, desta forma, a redução deste caractere pode ser considerada como uma linha de defesa contra o déficit hídrico.

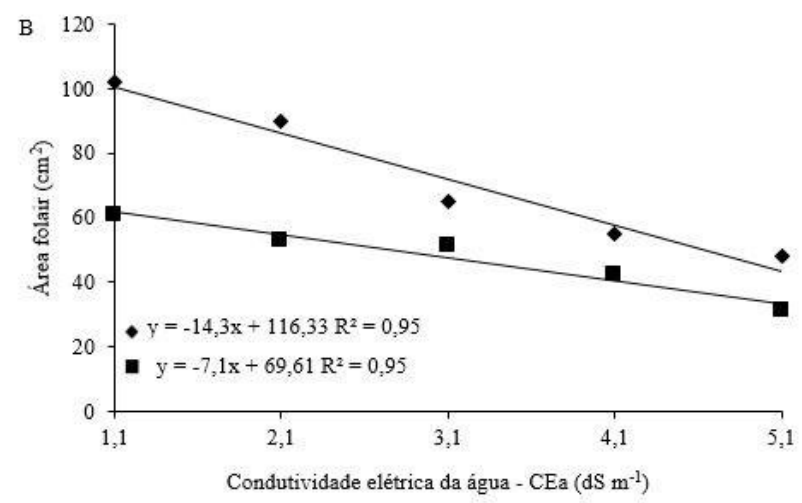

Figura 2. Diâmetro do caule (2A) e área foliar (2B) de fava irrigada com água salina sob diferentes regimes hídricos $100 \%$ ( ) e $50 \%$ ETc (ロ) aos 45 dias após o plantio.

Provavelmente, a inibição da área foliar deve ter sido provocada, em maior parte, pelos efeitos tóxicos dos sais absorvidos pelas cultivares, pela baixa capacidade de ajustamento osmótico da cultura ou pela redução do potencial total da água provocado 
pelo aumento da concentração salina, gerando ainda um distúrbio fisiológico na planta e comprometendo a abertura dos estômatos (SOUSA et al., 2014).

Quanto ao efeito do aumento da concentração de sais na água de irrigação sobre a variável massa seca da parte aérea (MSPA), constatou-se uma redução decrescente, sendo um modelo do tipo linear, a equação que melhor representou a resposta das plantas (Figura 3). Resultados semelhantes foram evidenciados por Pereira Filho et al. (2017), que também constataram um modelo do tipo linear nas respostas de genótipos de feijoeiro à salinidade associada ao manejo da irrigação em dois regimes hídricos (100 e 50\% da ETc).

Lacerda et al. (2011), descrevem que a redução da matéria seca da parte aérea nas culturas irrigadas com água salina está relacionada ao desvio de energia em decorrência do aumento dos níveis de salinidade do solo; logo, a redução nos valores da matéria seca da parte aérea pode ser o reflexo do custo metabólico de energia. Os resultados obtidos na presente pesquisa são condizentes com o fato de que a salinidade e/ou déficit hídrico, além de reduzir a produção de biomassa total, pode também alterar a partição de fotoassimilados entre as diferentes partes das plantas (SILVA et al., 2013).

O estresse salino e o déficit hídrico inibem ou retardam o crescimento das plantas devido aos efeitos iônico e osmótico (PEDROTTI et al., 2015). Em situações de baixa disponibilidade de água, a absorção é comprometida pela redução dos potenciais hídricos e, consequentemente, o crescimento das plantas é afetado pela diminuição da expansão e do alongamento celular (MOTERLE et al., 2008). O estresse salino pode também provocar uma toxicidade nos tecidos devido ao acúmulo em excesso de íons $\mathrm{Na}^{+}$e $\mathrm{Cl}^{-}$, afetam outros processos fisiológicos e metabólicos dos tecidos embrionários, incluindo a divisão e a diferenciação celular, a atividade de enzimas e a captação e distribuição de nutrientes (VOIGT et al., 2009).

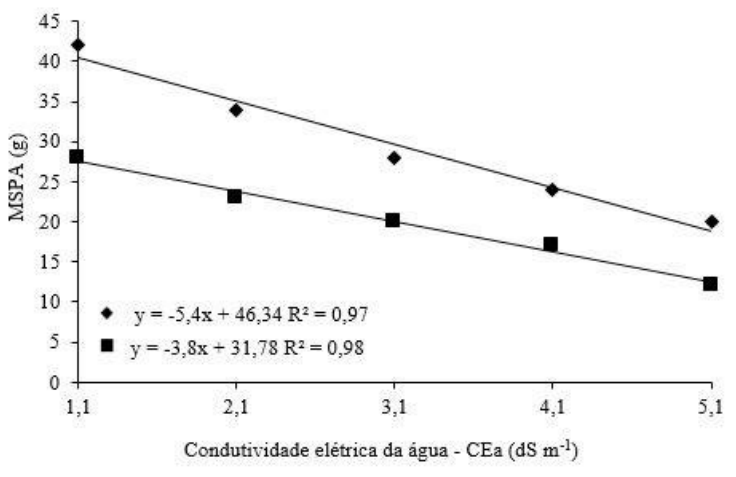

Figura 3. Massa seca da parte aérea de fava irrigada com água salina sob diferentes regimes hídricos $-100 \%$ ETo ( ) e 50\% ETo (•) aos 45 dias após o plantio.

A redução nas características de crescimento inicial do feijão fava (Figura 1A, 1B, 2A, 2B e 3), evidência uma resposta da cultura ao estresse hídrico e salino, como forma de garantir a absorção de água do solo para manter, parcialmente, a atividade fisiológica das plantas. Com a redução das características vegetativas de crescimento inicial, a cultura procurou desenvolver um mecanismo de adaptação à situação adversa, permitindo mesmo que em baixas proporções a extração da água no solo.

Segundo Garcia et al. (2009), a redução no crescimento inicial das plantas tanto sob estresse hídrico como salino, implica em dispêndio elevado de energia pela planta para manter, mesmo que em nível crítico, sua turgescência. Essa inconveniência sob déficit hídrico e/ou salino é adicional à energia requerida para absorver água da solução de um solo em capacidade de campo sob condições favoráveis de disponibilidade de água no solo. Dessa forma, as plantas exerceram maior força de embebição para extrair do solo sob deficiência hídrica causada pelo excesso de sais ou mesmo falta de água, uma unidade de massa de água comparativamente ao esforço para extraí-la sob condições favoráveis de potencial total da água no solo.

A condutividade elétrica do solo (CEes) aumentou significativamente com o teor salino da água de irrigação, sendo o modelo linear crescente o que melhor representou os dados desta variável (Figura 4). $\mathrm{O}$ valor estimado para a CEes no tratamento 


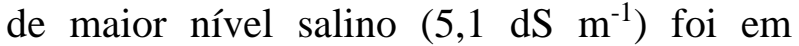
média 3,7 vezes maior do que o valor encontrado no menor nível salino $\left(1,1 \mathrm{dS} \mathrm{m}^{-1}\right)$. Resultados semelhantes são apresentados por Linhares et al. (2013), ao verificarem resposta linear crescente da condutividade elétrica do solo cultivado com berinjela irrigada com águas salinas.

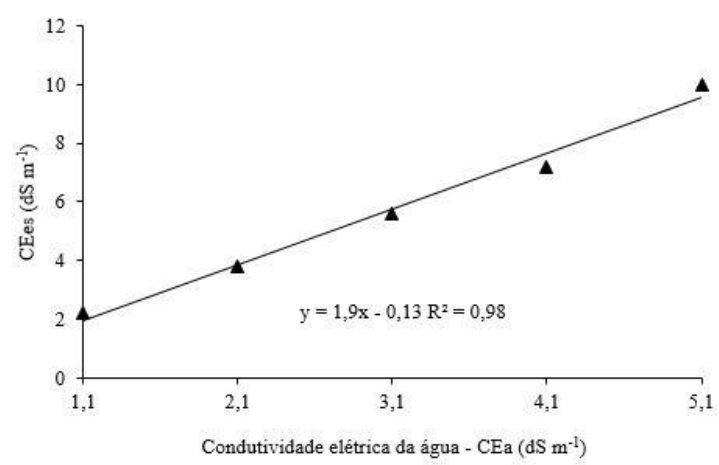

Figura 4. Condutividade elétrica do extrato de saturação do solo cultivado com fava irrigada com água salina em diferentes concentrações de sais aos 45 dias após o plantio.

Vale ressaltar, que o acúmulo de sais no solo provoca a redução dos fatores morfológicos da planta, além de afetar o desenvolvimento das raízes da cultura como afirma Silva et al. (2013), em estudos sobre o ajustamento osmótico da cultura da beterraba.

$\mathrm{Na}$ Figura 5 observa-se os valores médios da condutividade elétrica do solo sob os regimes hídricos de 100 e 50\% da ETc. O maior valor de condutividade elétrica $(7,18 \mathrm{dS}$ $\mathrm{m}^{-1}$ ) foi observado no tratamento que recebeu um regime de irrigação de $50 \%$ da ETc. Podese inferir que tal fato ocorreu devido à retenção dos sais da água de irrigação, uma vez que em tal condição, não foram observadas a lixiviação dos sais por meio da água percolada nos vasos. Resultados semelhantes são apresentados por Pereira Filho et al. (2017a) ao constatarem aumento da condutividade elétrica do solo cultivado com feijão de corda com a diminuição do regime hídrico de 100 para 50\% da ETc associados a água de irrigação com diferentes concentrações de sais.

Holanda Filho et al. (2011) estudando os atributos químicos do solo, Latossolo Amarelo Eutrófico, irrigado com água salina em diferentes lâminas aplicadas (110, 120, 130, 140 e $150 \%$ da ETc), constataram aumento da salinidade na profundidade de 00,20 m, evidenciando que as lâminas de irrigação superiores à lâmina de evapotranspiração da cultura não foram suficientes para lixiviação dos sais.

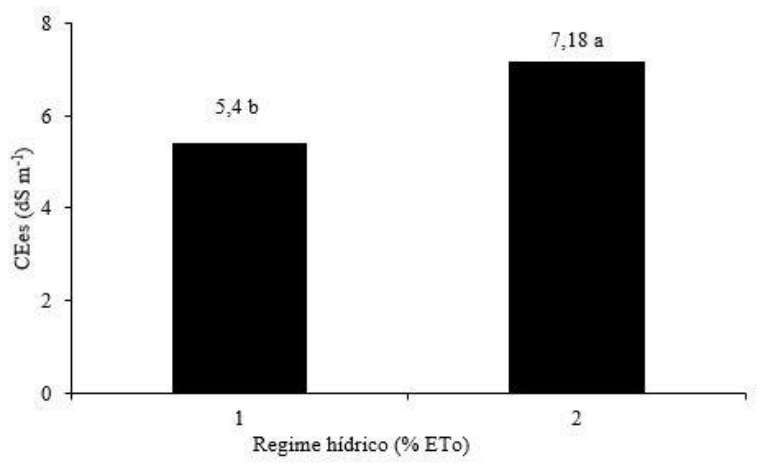

Figura 5. Condutividade elétrica do extrato de saturação do solo cultivado com fava irrigada com água salina sob diferentes regimes hídricos - 100\% ( ) e 50\% ETc (匹) aos 45 dias após o plantio.

Rhoades et al. (2000) alertam que a diminuição do potencial osmótico associada a frações de lixiviação pequenas e ao uso de águas de irrigação salinas, torna-se especialmente perigoso, porque o nível de "estresse crítico" do potencial total será alcançado mais rapidamente, principalmente para culturas sensíveis à salinidade.

$\mathrm{O}$ resultado obtido no regime hídrico de $100 \%$ da ETc deu-se, pela maior lixiviação sobre o acúmulo de sais do solo. Pois, de acordo com Carvalho et al. (2012), o excedente da água de irrigação lixivia o excesso de sais no perfil do solo, resultando em menor efeito da salinidade no ambiente radicular, o que favorece o crescimento e o desenvolvimento da cultura.

\section{CONCLUSÕES}

O crescimento inicial da cultura da fava foi prejudicado pelo aumento da concentração de sais na água de irrigação sob regime hídrico de $50 \%$ da ETc. 
A condutividade elétrica do solo é elevada pela redução no manejo da irrigação com águas salinas no regime hídrico de 100 para $50 \%$ da ETc.

\section{REFERÊNCIAS BIBLIOGRÁFICAS}

BERNARDO, S.; SOARES, A. A; MANTOVANI, E. C. Manual de irrigação. 8.ed. Viçosa: Editora UFV, 2008. 625p.

CARVALHO, J. F.; TSIMPHO, C. J.; SILVA, E. F de F.; MEDEIROS, P. R. F.; SANTOS, M. H. V.; SANTOS, A. N. Produção e biometria do milho verde irrigado com água salina sob frações de lixiviação. Revista Brasileira de Engenharia Agrícola e Ambiental, v.16, n.4, p.368- 374, 2012. http://dx.doi.org/10.1590/S141543662012000400006.

COELHO, J. B. M.; BARROS, M. de F. C.; BEZERRA NETO, E.; CORREA, M. M. Comportamento hídrico e crescimento do feijão vigna cultivado em solos salinizados. Revista Brasileira de Engenharia Agrícola e Ambiental, v.17, n.4, p.379-385, 2013. http://dx.doi.org/10.1590/S1415-

43662013000400004.

COSTA, A. R. F. C.; MEDEIROS, J. F. de. Água salina como alternativa para irrigação de sorgo para geração de energia no Nordeste brasileiro. Water Resources and Irrigation Management, v. 6, n. 3, p. 169-177, 2017.

EMPRESA BRASILEIRA DE PESQUISA AGROPECUÁRIA - EMBRAPA. Sistema brasileiro de classificação de solos. 3.ed. Brasília, 2013. 353p.

FERNANDES, V. L. B. Recomendações de adubação e calagem para o estado do Ceará. Fortaleza: UFC, 1993. 248 p.

GARCIA, G. de O.; MARTINS FILHO, S.; NAZÁRIO, A. A.; MORAES, W. B.; GONÇALVES, I. Z.; MADALÃO, J. C. Estresse hídrico e salino na produção relativa e potencial de água na folha do feijoeiro. Irriga, v. 14, n. $4, \quad$ p. $470-480,2009$. http://dx.doi.org/10.15809/irriga.2009v14n4p4 70-480.

HOLANDA FILHO, R. S. F.; SANTOS, D. B.; AZEVEDO, C. A. V.; COELHO, E. F.; LIMA, V. L. A. Água salina nos atributos químicos do solo e no estado nutricional da mandioqueira. Revista Brasileira de Engenharia Agrícola e Ambiental, v.15, n.1, p.60-66,

2011.

http://dx.doi.org/10.1590/S1415-

43662011000100009.

IBGE (INSTITUTO BRASILEIRO DE GEOGRAFIA E ESTATÍSTICA). Produção Agrícola

$2016 . \quad$ Disponível em: $<$ http://www.sidra.ibge.gov.br/bda>. Acesso em: 06 jan. 2018.

LACERDA, C. F.; SOUSA, G. G.; SILVA, F. L. B.; GUIMARÃES, F. V. A.; SILVA, G. L.; CAVALCANTE, L. F. Soil salinization and maize and cowpea yield in the crop rotation system using saline waters. Engenharia Agrícola, v.31, n.4, p.663-675, 2011. http://dx.doi.org/10.1590/S010069162011000400005.

LINHARES, P. S. F.; ALVES, R. C.; MEDEIROS, A. M. A.; LIMA, L. A.; BEZERRA, F. M. S.; CAVALCANTE, A. L. G.; OLIVEIRA, F. de A. Alterações químicas no Argissolo cultivado com berinjela irrigada com águas salinas. Agropecuária Científica no Semi-Árido, v. 9, n. 3, p. 55-61, 2013. http://dx.doi.org/10.30969/acsa.v9i3.394.

MORTELE, L. M.; SANTOS, R. F.; BRACCINI, A. L.; SCAPIM, C. A.; BARBOSA, M. C. Efeito da aplicação de biorregulador no desempenho agronômico e produtividade da soja. Acta Scientia Agronomy, v.30, p.701-709, 2008. http://dx.doi.org/10.4025/actasciagron.v30i5.5 971.

OLIVEIRA, F. de A.; PINTO, K. S. de O.; BEZERRA, F. M. S.; LIMA, L. A.; CAVALCANTE, A. L. G.; OLIVEIRA, M. K. 
T.; MEDEIROS, J. F. Tolerância do maxixeiro, cultivado em vasos, à salinidade da água de irrigação. Revista Ceres, v. 61, n.1, p. 147-154, 2014. http://dx.doi.org/10.1590/S0034737X2014000100020.

OLIVEIRA, F. de A.; GUEDES, R. A. A.; GOMES, L. P.; BEZERRA, F. M. S.; LIMA, L. A.; OLIVEIRA, M. K. T. Interação entre salinidade e bioestimulante no crescimento inicial de pinhão-manso. Revista Brasileira de Engenharia Agrícola e Ambiental, v.19, n.3, p.204-210, 2015. http://dx.doi.org/10.1590/1807-

1929/agriambi.v19n3p204-210.

OLIVEIRA, F. N.; TORRES, S. B.; BEBEDITO, C. P. Caracterização botânica e agronômica de acessos de feijão-fava, em Mossoró, RN. Revista Caatinga, v. 24, n. 1, p. 143-148, 2011.

PEDROTTI, A.; CHAGAS, R. M.; RAMOS, V. C.; PRATA, A. P. N.; LUCAS, A. A. T.; SANTOS, P. B. Causas e consequências do processo de salinização dos solos. Revista Eletrônica em Gestão, Educação e Tecnologia Ambiental, v. 19, n. 2, p. 13081324 , 2015. http://dx.doi.org/105902/2236117016544.

PEREIRA, M. R. R.; MARTINS, C. C.; SOUZA, G. S. F.; MARTINS, D. Influência do estresse hídrico e salino na germinação de Urochloa decumbens e Urochloa ruziziensis. Bioscience Journal, v. 28, n. 4, p. 537-545, 2012.

PEREIRA FILHO, J. V.; BEZERRA, F. M. L.; SILVA, T. C.; PEREIRA, C. C. M. de S. Crescimento vegetativo do feijão-caupi cultivado sob salinidade e déficit hídrico. Revista Brasileira de Agricultura Irrigada, v.11, $\mathrm{n}^{\circ} .8, \quad$ p. 2217 - 2228, 2017. http://dx.doi.org/10.7127/rbai.v11N800718.

PEREIRA FILHO, J. V.; BEZERRA, F. M. L.; SILVA, T. C.; PEREIRA, C. C. M. S. CHAGAS, K. L. Alteração química do solo cultivado com feijão caupi sob salinidade e dois regimes hídricos. Revista Brasileira de Agricultura Irrigada, v.11, $\mathrm{n}^{\mathrm{o}} .8$, p. 2206 2216 , $2017 \mathrm{a}$. http://dx.doi.org/10.7127/rbai.v11n800717.

RHOADES, J. P.; KANDIAH, A.; MASHALI, A. M. The use saline waters for crop production. Trad.: GHEYI, H. R.; SOUSA, J. R.; QUEIROZ, J. E. Campina Grande: UFPB, 2000. 117p.

RICHARDS, L. A. Diagnostico y rehabilitación de suelos salinos y sódicos. México: Departamento de Agricultura de los Estados Unidos de América, 174p (Manual de Agricultura, 60), 1954.

SILVA, A. L.; NASCIMENTO, M. N.; TANAN, T. T.; OLIVEIRA, U. C.; LIMA, J. do C. Efeito da salinidade da água de irrigação na produção de alface crespa. Enciclopédia Biosfera, v.14 n.26; p. 328-337, 2017. http://dx.doi.org/10.18677/EnciBio_2017B28.

SILVA, A. O. da; KLAR, A. E.; SILVA, E. F. de F. e. Produção da cultura da beterraba irrigada com água salina. Engenharia na agricultura, v.21, n.3, p. 271-279, 2013. DOI: http://dx.doi.org/10.13083/1414-

3984.v21n03a06.

SNYDER, R. L. Equation for evaporation pan to evapotranspiration conversions. Journal of Irrigation and Drainage Engineering, v.118, $\mathrm{p}$ 977-980, 1992. https://doi.org/10.1061/(ASCE)07339437(1992)118:6(977).

SOUSA, C. C. M.; PEDROSA, E. M. R.; ROLIM, M. M.; OLIVEIRA FILHO, R. A.; SOUZA, M. A. L. M.; PEREIRA FILHO, J. V. Crescimento e respostas enzimáticas do feijoeiro caupi sob estresse hídrico e nematoide de galhas. Revista Brasileira de Engenharia Agrícola e Ambiental, v.19, n.2, p.113-118, 2015 . http://dx.doi.org/10.1590/18071929/agriambi.v19n2p113-118. 
SOUSA, G. G.; VIANA, T. V. A.; LACERDA, C. F.; AZEVEDO, B. M.; SILVA, G. L.; COSTA, F. R. B. Estresse salino em plantas de feijão-caupi em solo com fertilizantes orgânicos. Revista Agro@mbiente On-line, v. 8, n. 3, p., 359367, 2014. http://dx.doi.org/10.18227/19828470ragro.v8i3.1824.

TAIZ, L.; ZEIGER, E.; MOLLER, I.; MURPHY, A. Fisiologia e desenvolvimento vegetal. 6.ed. Porto Alegre: Artmed, 2017. $888 \mathrm{p}$.
TESTER, M.; DAVENPORT, R. $\mathrm{Na}^{+}$ tolerance and $\mathrm{Na}^{+}$transport in higher plants. Annals of Botany, v.91, p.503-527, 2003. http://dx.doi.org/10.1093/aob/mcg058.

VOIGT, E. L.; ALMEIDA, T. D.; CHAGAS, R. M.; PONTE, L. F. A.; VIÉGAS, R. A.; SILVEIRA, J. A. G. Source-sink regulation of cotyledonary reserve mobilization during cashew (Anacardium occidentale) seedling establishment under $\mathrm{NaCl}$ salinity. Journal of Plant Physiology, v.166, p.80-89, 2009. http://dx.doi.org/10.1016/j.jplph.2008.02.008. 